\title{
Blowing in a bottle
}

\author{
Gonzalo Varela, $\mathrm{MD}, \mathrm{PhD}$
}

From the Department of Surgery, School of Medicine, Salamanca University, Salamanca, Spain.

Disclosures: Author has nothing to disclose with regard to commercial support.

Received for publication Dec 28, 2017; accepted for publication Jan 9, 2018; available ahead of print Feb 1, 2018.

Address for reprints: Gonzalo Varela, MD, PhD, School of Medicine, Salamanca University, Paseo de San Vicente

58,37007 Salamanca, Spain (E-mail: gvs@usal.es).

J Thorac Cardiovasc Surg 2018;155:2190

$0022-5223 / \$ 36.00$

Copyright (c) 2018 by The American Association for Thoracic Surgery

https://doi.org/10.1016/j.jtcvs.2018.01.011

In this issue of the Journal, Mentzer and colleagues ${ }^{1}$ underline the relevance of understanding the physiology of transpulmonary pressure and lung compliance to apply more effective treatment to patients with persistent pulmonary air leak (PAL) or postoperative pneumothorax. Mentzer and colleagues' article ${ }^{1}$ has the merit of facilitating the understanding of pleural mechanics and the influence of pulmonary compliance and chest wall and diaphragm interactions on pleural pressures and air flow. In addition, Mentzer and colleagues ${ }^{1}$ discuss the basics for chest tube management and some of the available procedures to facilitate the apposition of visceral and parietal pleural surfaces after lung resection. Personally, I do not rely on the usefulness of dividing the inferior pulmonary ligament to decrease the risk of apical pleural spaces and air leak after upper lobe resection. In fact, the systematic review published by Khanbhai and associates ${ }^{2}$ cited by Mentzer and colleagues ${ }^{1}$ concludes that "there is no convincing evidence that dissection of the pulmonary ligament in an upper lobectomy significantly improves outcomes and reduces complications."

PAL is the most frequent complication after anatomic lung resection and can be associated to undesirable adverse events and increased costs of care. Our team showed initial enthusiasm on the use of digital thoracic drainages to measure intrapleural pressure after lobectomy, surmising that the first 48-hour trend in pleural pressure could be correlated with the occurrence of PAL. After evaluation of preliminary results, we were unable to validate the hypothesis but concluded that PAL could be accurately predicted through a simple statistical model derived from clinical data and air leak measurements on conventional and less expensive systems, ${ }^{3}$ allowing early patient discharge and ambulatory management with portable chest drainage. ${ }^{4}$

Recently, initial experiences have been reported with implantation of endobronchial one-way valves for the treatment of PAL in selected cases. Although we are still awaiting publication of the ongoing randomized studies, ${ }^{5}$ some authors conclude that the use of endobronchial valves is effective for patients with prolonged PAL after lung resection. ${ }^{6,7}$ Unfortunately, implantation of endobronchial

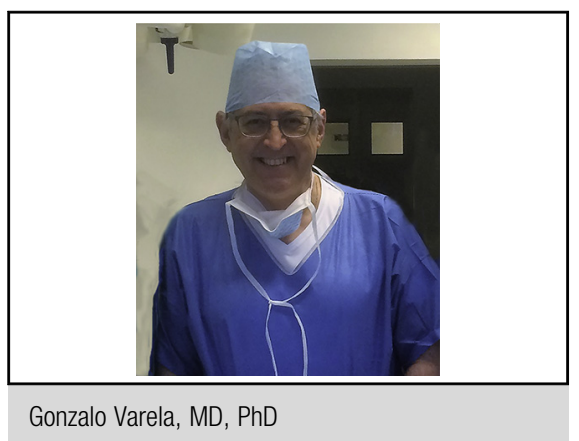

Central Message

Prolonged air leak is the most frequent complication after anatomic lung resection. Its occurrence can be accurately predicted to decrease its impact on patient health and costs of care.

See Article page 2182.

valves can be followed by migration or expectoration of valves, oxygen desaturation, atelectasis, and infection of the related lung, although no deaths related to the valves have been reported to date. ${ }^{8}$ In addition, in some hands fewer than $50 \%$ of the patients had complete resolution of the problem, ${ }^{6}$ and as many as 8 or 12 one-way valves per patient were needed for successful therapy, ${ }^{9,10}$ posing some doubts as to the efficiency of the procedure.

\section{References}

1. Mentzer SJ, Tsuda A, Loring SH. Pleural mechanics and the pathophysiology of air leaks. J Thorac Cardiovasc Surg. 2018;155:2182-9.

2. Khanbhai M, Dunning J, Yap KH, Rammohan KS. Dissection of the pulmonary ligament during upper lobectomy: is it necessary? Interact Cardiovasc Thorac Surg. 2013;17:403-6.

3. Rodríguez M, Jiménez MF, Hernández MT, Novoa NM, Aranda JL, Varela G. Usefulness of conventional pleural drainage systems to predict the occurrence of prolonged air leak after anatomical pulmonary resection. Eur J Cardiothorac Surg. 2015;48:612-5.

4. Varela G, Jiménez MF, Novoa N. Portable chest drainage systems and outpatient chest tube management. Thorac Surg Clin. 2010;20:421-6.

5. Spiration Valves Against Standard Therapy (VAST). Available at: https:// clinicaltrials.gov/ct2/show/NCT02382614. Accessed December 28, 2017.

6. Travaline JM, McKenna RJ Jr, De Giacomo T, Venuta F, Hazelrigg SR, Boomer M, et al. Endobronchial Valve for Persistent Air Leak Group. Treatment of persistent pulmonary air leaks using endobronchial valves. Chest. 2009;136: 355-60. Erratum in: Chest. 2009;136:950.

7. Dooms CA, Decaluwe H, Yserbyt J, De Leyn P, Van Raemdonck D, Ninane V. Bronchial valve treatment for pulmonary air leak after anatomical lung resection for cancer. Eur Respir J. 2014;43:1142-8.

8. Ding M, Gao YD, Zeng XT, Guo Y, Yang J. Endobronchial one-way valves for treatment of persistent air leaks: a systematic review. Respir Res. 2017;18:186.

9. Gilbert CR, Casal RF, Lee HJ, Feller-Kopman D, Frimpong B, Dincer HE, et al. Use of one-way intrabronchial valves in air leak management after tube thoracostomy drainage. Ann Thorac Surg. 2016;101:1891-6.

10. Reed MF, Gilbert CR, Taylor MD, Toth JW. Endobronchial valves for challenging air leaks. Ann Thorac Surg. 2015;100:1181-6. 